\title{
Olhares de crianças baianas sobre família ${ }^{1}$
}

\author{
Lúcia Vaz de Campos Moreira ${ }^{2}$ \\ Elaine Pedreira Rabinovich \\ Universidade Católica do Salvador, Salvador-BA, Brasil \\ Célia Nunes Silva \\ Universidade Federal da Bahia, Salvador-BA, Brasil
}

\begin{abstract}
Resumo: Este estudo investigou os significados que 60 crianças baianas, de 6 a 12 anos, atribuíam aos pais, mães, irmãos, avós e família. Os participantes foram divididos em quatro grupos de 15 crianças: dois de Salvador-BA, cujos pais tinham nível sócio-educacional baixo e alto, e dois provenientes do interior da Bahia com os mesmos níveis sócio-educacionais. As crianças foram entrevistadas individualmente conforme roteiro semi-estruturado. Investigou-se a composição da família e o local da moradia com os responsáveis. Os dados evidenciam que as crianças residem com a família nuclear, mas têm relações estreitas com a família extensa; a família é concebida como quem cuida e apóia; a mãe cuida, educa e é afetiva; o pai e o avô são lúdicos; as avós agradam; os irmãos brincam, ajudam e ensinam, embora também atritem, mas são companhias com as quais se conta sempre.
\end{abstract}

Palavras-chave: família, membros da família, infância.

\section{Perspectives of children from Bahia, Brazil about family}

\begin{abstract}
This study investigated the meanings 60 children, 6 to 12 years old, attribute to their fathers, mothers, siblings, grandparents and families. Participants were divided in four groups of 15 children each: two groups with children from Salvador, Bahia, Brazil and whose parents had high and low socio-educational level, and two from the interior of Bahia with the same socio-educational levels. Children were individually interviewed according to semi-structured questionnaire. Family composition and local of residence were investigated with parents. Data evidence that children live with their nuclear family but have close relationship with their extended family; the family is conceived as who cares and supports; the mother cares, disciplines and is affective; the father and grandfather play; grandmothers please; siblings play, help and teach, though there is misunderstanding, they are those whom one can always rely on.
\end{abstract}

Keywords: family, family members, childhood.

\section{Visiones de niños de la Bahia, Brasil sobre familia}

Resumen: El estudio investigó los significados que 60 niños baianos, de 6 a 12 años, atribuyen a los padres, madres, hermanos, abuelos y familia. Los participantes fueron divididos en cuatro grupos de 15 niños: dos de Salvador, Bahia cuyos padres tenían nivel socio educacional bajo y alto, y dos provenientes del interior da Bahia con los mismos niveles socio educacional. Los niños fueran entrevistados individualmente conforme dirección semi estructurado. La composición de la familia y local de residencia fueron obtenidos de los responsables. Los dados evidencian que los niños viven con la familia nuclear, pero mantienen estrechas relaciones con la familia extendida; la familia es entendida como quien cuida y apoya; la madre cuida educa y es afectiva; el padre y el abuelo son lúdicos; las abuelas agradan; los hermanos jugan, ayudan y enseñan, aunque riñen, son las compañías con las cuales siempre se puede contar.

Palabras clave: familia, miembros de la familia, infancia.

Muitas investigações foram desenvolvidas sobre as crianças, contudo, apesar da ênfase dada à infância pelas teorias co-construtivistas que perpassam a Psicologia em geral, especialmente a Psicologia do Desenvolvimento, poucas foram realizadas com elas a partir de perspectivas por elas enunciadas. Nesta direção, Carvalho, Beraldo, Pedrosa e Coelho (2004) dedicaram-se a analisar o potencial (positivo e negativo) da utilização de entrevistas com crianças, técnica pouco explorada em nossa literatura, segundo estas autoras.

\footnotetext{
1 As autoras agradecem a colaboração da Profa. Dra. Ana Maria Almeida Carvalho, das mestrandas Daisy Alves, Ivone da Silva, Leonor Guimarães, Rita de Cássia de Moraes, Roberta Chaves e da bolsista de iniciação científica (apoio FAPESB) Stella Pinheiro.

2 Endereço para correspondência:

Profa. Dra. Lúcia Vaz de Campos Moreira. Universidade Católica do Salvador. Superintendência de Pesquisa e Pós-graduação. Programa de Pós-graduação em Família na Sociedade Contemporânea. Av. Cardeal da Silva, 205. CEP: 40231-902. Salvador-BA, Brasil. E-mail: luciam@usp.br
}

Concluíram que o uso da entrevista depende "do tipo de pergunta que se pretende responder e da qualidade e adequação dos recursos de amostragem, registro e análise aplicados à coleta e interpretação dos dados" (Carvalho e cols., 2004, p. 299). Afirmaram ainda que a entrevista é o principal instrumento de coleta, quando se deseja apreender as concepções e percepções das crianças a respeito de determinado fenômeno. Tal é o nosso propósito: perguntar às crianças como estão apreendendo o fenômeno "família".

Estudos que investigam concepções de pais e mães são comuns (Moreira, 1999, 2005), porém, são necessárias investigações sobre o tema a partir das crianças. Assim como é relevante para a família a relação conjugal, também a paternidade e a filiação o são. Deste modo, decidimos investigar, junto aos filhos, como esses estão vendo a família em um momento em que a sociedade inteira se interroga sobre isto.

Uma das mudanças fundamentais no Ocidente, no século XX, foi o lugar ocupado pelas crianças, que passaram 
a ser cada vez mais importantes na sociedade e aos olhos da lei, em paralelo, ocorreram mudanças nas relações dos indivíduos quanto à sexualidade e aos lugares ocupados por homens e mulheres na sociedade (Godelier, 2004, p. 565). A criança torna-se "um rei", escolhe a marca do carro da família, o que esta consome como alimento, por exemplo. "A criança torna-se uma consumidora e também uma produtora, pois ela orienta o que as indústrias vão produzir" (David, 2001, p. 1).

Portanto, não causa espanto que a demografia tenha sido obrigada a encarar a criança como uma variável em si: "As transformações dos modos de vida familiares levaram a demografia a reconstruir uma variável que ela ignorava até então, mas que parece se tornar incontornável, pois aparece como o único ponto fixo da célula familiar" (Sirota, 2001, p. 25), dado que retira a criança de sua invisibilidade, não apenas estatística, mas como agente e ator. No Brasil, Biasoli-Alves (2008) constatou que as práticas de educação utilizadas pelas famílias com as gerações mais novas sofreram mudanças ao longo do século XX, passando-se a atribuir às crianças certa autonomia e controle de sua vida, dificilmente cogitáveis poucos anos atrás.

Krantz e Rasmusson (1995) apontaram que há três abordagens possíveis em pesquisas envolvendo crianças e o ambiente construído: a quantitativa, orientada ao bem-estar; a normativa; e a fenomenológica. Estas autoras consideram que os métodos derivados das ciências naturais transformaram as crianças em objetos. Entrevistas com crianças foram consideradas não científicas e não válidas. Com a expansão da necessidade de se incluir o contexto (Tudge, 2008), os pesquisadores passaram a aceitar, gradualmente, a utilização de entrevista, de observação e de outros métodos, inclusive com a participação de crianças.

Embora na literatura nacional haja poucos estudos envolvendo a criança como sujeito de seu conhecimento, nos países nórdicos ela tem sido chamada a opinar sobre tópicos variados. Por exemplo, Hviid (2006), da Noruega, pesquisou a dimensão do tempo entrevistando crianças quanto ao seu próprio desenvolvimento, enquanto Skantze (1995), da Suécia, pesquisou como elas vivenciam e interpretam a arquitetura da cidade.

Diretamente relacionado ao tema do presente estudo, Mann, Borduin, Borduin e Sylvester (1992) estudaram os conceitos de família por crianças, concluindo que o nível de desenvolvimento cognitivo foi mais importante para a compreensão da família do que as experiências específicas derivadas de viver com ela.

Um estudo de Rabinovich e Moreira (2008), visando conhecer os significados de família atribuídos por crianças de 6 a 10 anos, oriundas de diferentes camadas sociais e locais, moradoras de três localidades no estado de São Paulo, concluiu que o principal significado atribuído à família é o de cuidar. Cuidar significa alimentar, criar e mesmo educar, em um sentido mais amplo, deriva de cultivar, fazer germinar e florescer. Quanto aos genitores, a mãe emergiu como mais importante e mais atarefada, o pai, nas crianças de nível sócio-educacional superior, apareceu como amigo e, mais do que a mãe, foi visto como provedor. Os irmãos foram os membros familiares mais consistentemente presentes. Os avôs levavam para passear, transmitiam conhecimentos e as avós agradavam, mimavam, fazendo todas as vontades. Assim, ambos os avós foram positivamente retratados.

Outro estudo, realizado em um contexto bem diverso, com adultos que viveram até a maioridade em Aldeias SOS (Cruz, 2008), encontrou igualmente que os participantes consideram que a família é quem cuida da pessoa, concluindo que relações de cuidado e acolhimento podem gerar pessoas que procurarão também cuidar.

Tais resultados estão de acordo com a literatura sobre a família. Arriagada (2000), a partir de estudos com famílias latino-americanas, aponta o declínio do modelo patriarcal, uma vez que houve a incorporação maciça das mulheres no mercado de trabalho; o fim do sistema de provedor único da casa; e o aumento do número de lares chefiados por mulheres, em sua maioria, monoparentais. Embora as famílias nucleares continuem predominantes, apresentam diferentes estruturas: famílias reconstituídas, as chefiadas por mulheres, as sem filhos, as constituídas por três gerações, entre outras. Devido ao processo de urbanização, houve crescimento das casas unipessoais e diminuíram aquelas com famílias extensas e compostas, a autora observou ainda o decréscimo das taxas de natalidade a partir dos anos 1970. Além disso, as funções de cuidado e de socialização inicial dos filhos são compartilhadas cada vez mais com outros agentes sociais como a escola, outras pessoas da família e não familiares, havendo novas relações entre pais e filhos, com aumento dos direitos dos filhos e perda da relevância das relações de hierarquia e submissão.

Para Welti (2002), uma das mudanças mais relevantes na família latino-americana, fruto de uma combinação de fatores demográficos e econômicos, é o fato de três sucessivas gerações (crianças, pais e avós) co-habitarem em uma proporção significativa de moradias.

Jablonski $(1999,2007)$ também reflete sobre o papel masculino e feminino na relação conjugal, na divisão de trabalhos domésticos e no cuidado dos filhos. Em concordância com os achados de Rabinovich e Moreira (2008), aponta que, na atualidade, o homem ocupa posição mais lúdica frente aos filhos, não sendo o único provedor da família, função agora compartilhada com a companheira. A mulher encontra-se mais atarefada, pois embora no discurso haja uma divisão mais igualitária das tarefas domésticas e de cuidado com os filhos, na prática, a maior parte delas é desempenhada pela figura feminina.

O presente estudo visa, portanto, conhecer as significações que crianças, oriundas de diferentes locais e grupos sócio-culturais, atribuem à família. Mais especificamente, propõe-se explicitar a visão das crianças que habitam territórios diversos localizados no Estado da Bahia, referente a como percebem o que é família e como definem os diferentes 
membros que a compõem. Deste modo, espera-se contribuir para um entendimento mais amplo sobre a temática em questão.

Como objetivos específicos, a pesquisa procurou conhecer: (a) família: como as crianças a definem e quais os membros que julgam compô-la; (b) pai e mãe: como compreendem cada um deles; (c) irmãos: como é a experiência fraterna; (d) avô e avó: como vivenciam a relação com cada um deles.

\section{Método}

Trata-se de um estudo descritivo, realizado a partir de entrevistas semi-estruturadas e abertas, em que se buscou uma diversidade "ecológica" (Bronfenbrenner, 1979/1996, 2004), variando o local de moradia das crianças e o nível sócio-educacional de seus pais. Com a variação do local da moradia, procurou-se relacionar a compreensão de crianças sobre suas famílias com diferentes níveis de urbanização, que podem afetar, direta e indiretamente, o modo de vida familiar. O projeto foi submetido e aprovado pelo Comitê de Ética em Pesquisa da Universidade Católica do Salvador.

\section{Participantes}

Foram entrevistadas 60 crianças com idade variando entre 6 e 10 anos, sendo 24 do sexo masculino e 36 do feminino. Residiam no Estado da Bahia: metade morava na capital e outra metade em cidades do interior. As crianças foram divididas em quatro grupos: (a) Grupo 1: crianças da capital cujos pais apresentavam nível sócio-educacional alto (ensino superior completo ou titulação acima); (b) Grupo 2: crianças da capital cujos pais tinham nível sócio-educacional baixo ( $1^{\mathrm{a}}$ a $8^{\mathrm{a}}$ série do ensino fundamental); (c) Grupo 3: crianças do interior cujos pais apresentavam nível sócio-educacional alto; (d) Grupo 4: crianças do interior cujos pais tinham nível sócio-educacional baixo.

\section{Instrumentos}

Os instrumentos utilizados foram: (a) um roteiro sobre as concepções de família e de seus membros, respondido pelas crianças contendo as seguintes perguntas: (1) O que é família para você? (2) Como é a sua família? (3) O que é ser pai? (4) O que é ser mãe? (5) Você tem irmãos? ( ) Sim ( ) Não (6) Para que serve um irmão? (7) Como é ser irmão? (8) Você tem avós? ( ) Sim ( ) Não (9) Como é ser vovó? (10) Como é ser vovô?; (b) um questionário sócio-demográfico sobre a composição da família, local de moradia, conjunto de moradores, idade, sexo, escolaridade e profissão dos pais, respondido pelos pais ou responsáveis.

\section{Procedimento}

A captação das crianças ocorreu em seus contextos de vida cotidiana, tendo como critério de eleição a acessibilidade dos pesquisadores a elas. Os pesquisadores foram às casas das crianças ou às instituições educacionais por elas frequentadas, seus pais ou responsáveis foram convidados a autorizá-las a participar do estudo (até atingir o limite de 15 crianças em cada grupo). Os responsáveis responderam a um questionário sócio-demográfico e, posteriormente, foram realizadas entrevistas gravadas com as crianças, transcritas literalmente e analisadas.

As entrevistas foram realizadas pelas autoras e por mestrandas da Universidade Católica do Salvador (UCSal) na casa da criança ou em instituições educacionais. Os pais ou responsáveis consentiram sua participação após os devidos esclarecimentos e assinatura do Termo de Consentimento Livre e Esclarecido.

\section{Análise de dados}

As respostas às entrevistas foram agrupadas por temas ou categorias, segundo o procedimento de análise de conteúdo (Bardin, 1977), o que permitiu a construção de tabelas descritivas. Esses agrupamentos permitiram buscar as igualdades e as diferenças observadas nas categorias obtidas em sua variação por nível sócio-educacional e local de moradia. Vale ressaltar que este estudo procurou alguns aspectos peculiares do olhar de diferentes crianças às suas famílias sem a pretensão de construir uma nosologia por diferenças intragrupais. Contudo, na presença de características emergentes próprias a certas especificidades grupais, estas foram apontadas e descritas.

\section{Resultados e Discussão}

Os dados obtidos foram analisados verificando-se as frequências das respostas encontradas. Quem a criança considera fazer parte da família e com quem ela mora são apresentadas na Tabela 1. A família nuclear consiste aquela em que a criança reside com os genitores; a família ampliada corresponde à nuclear com avó; a extensa inclui outros parentes à família nuclear; e a monoparental refere-se à família composta por um genitor e seus filhos.

Embora a moradia compartilhada com família extensa represente uma parte pequena dos participantes, restrita às crianças cujos pais tinham nível sócio-educacional baixo, a maioria dos entrevistados, independente de classe ou local, descreve a família como extensa, o que parece indicar que a participação familiar não se restringe a quem mora na casa. Estudos anteriores (Rabinovich, 1994; Rabinovich \& Gallo, 2005) verificaram que, embora classificadas como moradias unifamiliares, vários núcleos familiares residiam proximamente, em um terreno coletivo, em casas de fundo ou sobre lajes, como vizinhos, ou nas proximidades. Deste modo, a perspectiva das crianças ao incluir outros parentes como parte da família confirma esses resultados, evidenciando a necessidade de incluí-los em estudos sobre família.

As famílias extensas, compartilhando moradias, teriam implicações diversas: na zona rural, significam núcleos familiares rurais ainda em funcionamento; na zona urbana de baixa renda, significam migrantes que moram juntos, talvez por falta de opção, como salientou Welti (2002). 
Tabela 1

Distribuição das frequências das respostas das crianças segundo quem faz parte da família e quem mora na casa

\begin{tabular}{lccccc}
\hline \multicolumn{1}{c}{ Tipo de família } & Grupo 1 & Grupo 2 & Grupo 3 & Grupo 4 & Total \\
\hline Quem faz parte da família & & & & & \\
Extensa & 9 & 13 & 7 & 8 & 37 \\
$\quad$ Nuclear & 4 & 2 & 6 & 7 & 19 \\
Ampliada & 2 & - & 2 & - & 4 \\
$\quad \mathrm{n}^{\text {0 de participantes }}$ & 15 & 15 & 15 & 15 & 60 \\
Quem mora na casa & & & & & \\
Nuclear & 13 & 10 & 12 & 10 & 45 \\
Ampliada & 2 & - & 3 & 2 & 7 \\
Extensa & - & 5 & - & 2 & 7 \\
Monoparental & - & - & - & 1 & 1 \\
$\quad \mathrm{n}^{0}$ de participantes & 15 & 15 & 15 & 15 & 60 \\
\hline
\end{tabular}

Ainda sobre a família, as concepções apresentadas pelos participantes foram agrupadas em oito categorias: (a) pessoas que cuidam: significando pessoas que colaboram umas com as outras, que se ajudam; (b) significado afetivo: lugar onde as pessoas manifestam amor, carinho, respeito, bondade e não maltratam; (c) grupo de pessoas que vivem juntas: família enquanto grupo de pessoas que vivem juntas, que cohabitam e são unidas, compartilhando, dividindo as experiências pessoais, ajudando-se mutuamente e tendo objetivos comuns; (d) fornece sustento: grupo de pessoas que dão alimento, vestimenta, moradia, ou mesmo que dão brinquedos, dentre outros; (e) educa a nova geração: família como função de educar sua prole; (f) sentido da vida: elemento mais importante, razão da própria vida; (g) estrutural definição legal: definição de família a partir de seus componentes; (h) diverte, passeia: família composta por pessoas que propiciam momentos agradáveis incluindo a realização de passeios e relacionamentos descontraídos e brincadeiras. As concepções apresentadas pelos participantes encontram-se na Tabela 2.

\section{Tabela 2}

Distribuição das frequências das respostas sobre as concepções de família apresentadas pelos quatro grupos

\begin{tabular}{|c|c|c|c|c|c|}
\hline O que é família & Grupo 1 & Grupo 2 & Grupo 3 & Grupo 4 & Total \\
\hline Pessoas que cuidam & 8 & 2 & 3 & 9 & 22 \\
\hline Significado afetivo & 6 & 1 & 3 & 5 & 15 \\
\hline Grupo de pessoas que vivem juntas & 3 & 2 & 4 & 3 & 12 \\
\hline Fornece sustento & 1 & 2 & 2 & 3 & 8 \\
\hline Educa a nova geração & 1 & - & 1 & 2 & 4 \\
\hline Sentido da vida & 1 & 2 & - & 1 & 4 \\
\hline Definição legal & 1 & - & 2 & - & 3 \\
\hline Diverte, passeia & - & - & 3 & - & 3 \\
\hline Não respondeu & 3 & 9 & 2 & 2 & 16 \\
\hline $\mathrm{n}^{\circ}$ de respostas $/ \mathrm{n}^{\circ}$ de participantes & $21(n=15)$ & $9(n=15)$ & $18(n=15)$ & $23(n=15)$ & $71(n=60)$ \\
\hline
\end{tabular}

Cuida, ajuda, apóia é o significado de família mais encontrado. Também são frequentes as concepções de significado afetivo e grupo de pessoas que vivem juntas. Uma menina (Grupo 1), de 7 anos, ilustra estes dados afirmando que "família são várias pessoas que gostam de você e que cuidam de você". Moreira (2005), ao abordar pais e mães com nível superior de escolaridade, também encontrou significativa diversidade de respostas, estando as maiores concentrações na definição de família enquanto grupo de pessoas que vivem juntas, já no presente estudo esta é apenas a terceira categoria mais referida. Assim, pode ser que uma definição de família baseada em relacionamentos mais do que em grupo de residência esteja sendo configurada neste grupo.
É importante destacar que o Grupo 2 (crianças da capital cujos pais tinham nível sócio-educacional baixo) apresentou dificuldades em responder tal questão. Como as crianças foram divididas pelo nível sócio-educacional dos pais, e as que ofereceram uma definição legal de família correspondem a meios mais favorecidos, pode-se contemplar os achados de Mann e cols. (1992), segundo os quais uma definição de família por parentesco implica que o nível de desenvolvimento cognitivo é mais importante para conceituação de família do que as experiências pessoais. Embora esses autores baseiem-se no fator idade, no caso brasileiro, o acesso à educação e o tipo de educação são diferenciadores de oportunidades para o desenvolvimento cognitivo infantil e adulto. 
De uma maneira inesperada, os grupos 1 e 4 tendem a convergir especialmente em suas respostas como "quem cuida" e "afetivo". Cuidar implica em prestar atenção e afeto, em reagir calorosamente às ações do outro, ambas definições compreendem um elemento relacional de reciprocidade (Sarti, 2004). No Grupo 3, aparecem três respostas que compreendem a família como locus da diversão, indicando que parte do implicado em cuidar e dar afeto está sendo consubstanciado em um modo de companheirismo. Assim, estes dados confirmam o estudo anterior (Rabinovich \& Moreira, 2008) em que, organizados em torno de um significado geral atribuído à família, o de cuidar, três conteúdos puderam ser agrupados holisticamente: grupo afetivo, relacionamento e fornecimento de sentido de vida, embora este último tenha estado menos presente nesta pesquisa.

Quanto às crianças do Grupo 2, as respostas se concentram em "não sei", podendo indicar tanto dificuldade de operar com o conceito em si quanto a falta de algumas condições para a emergência de uma percepção sobre a família. Com relação à concepção sobre pai, as respostas apresentadas pelos participantes foram agrupadas em oito categorias: (a) lúdico: caracterizando aqueles pais que brincam e passeiam com seus filhos e também os apontados como divertidos e engraçados; (b) cuidador: é o pai que cuida dos filhos, que os cria ou ainda os ajuda e protege quando necessário; (c) educador: é aquele que ensina a nova geração, assim como o que ajuda na realização de tarefas escolares; (d) provedor: o que fornece sustento ou dá as coisas que a criança necessita; (e) afetivo: caracterizado pelo pai que é carinhoso, amoroso; (f) disciplinador: é aquele que corrige, dá bronca, castiga ou bate; (g) trabalhador: define o pai pelo exercício profissional; (h) bom: caracteriza a positividade paterna, definindo-o como "gente boa"; (i) outros: nesta categoria foram agrupados os seguintes tipos de concepções, divididas conforme a quantidade de respostas, $\left(i_{1}\right)$ três respostas: tem características positivas como ser forte, inteligente, sabido, bonito; $\left(i_{2}\right)$ duas respostas: é amigo; é ausente; $\left(\mathrm{i}_{3}\right)$ uma resposta: filho ajuda o pai; tem características negativas, é chato; não é violento; dirige carro; respeita o filho; não faz nada. Estes dados estão apresentados na Tabela 3.

Tabela 3

Distribuição das frequências das respostas sobre as concepções de pai apresentadas pelos quatro grupos

\begin{tabular}{|c|c|c|c|c|c|}
\hline O que é pai & Grupo 1 & Grupo 2 & Grupo 3 & Grupo 4 & Total \\
\hline Lúdico & 4 & 1 & 9 & 5 & 19 \\
\hline Cuidador & 8 & 2 & 5 & 3 & 18 \\
\hline Educador & 3 & 1 & 3 & 7 & 14 \\
\hline Provedor & 1 & 5 & 2 & 4 & 12 \\
\hline Afetivo & 3 & 2 & 1 & 3 & 9 \\
\hline Disciplinador & 4 & 1 & 1 & 3 & 9 \\
\hline Trabalhador & 1 & 2 & 1 & 2 & 6 \\
\hline Bom & 1 & 4 & 1 & - & 6 \\
\hline Outros & 2 & 3 & 4 & 5 & 14 \\
\hline Não respondeu/não sabe & 1 & 1 & - & - & 2 \\
\hline $\mathrm{n}^{\circ}$ de respostas $/ \mathrm{n}^{\circ}$ de participantes & $27(n=15)$ & $21(n=15)$ & $27(n=15)$ & $32(n=15)$ & $107(n=60)$ \\
\hline
\end{tabular}

As percepções do pai como cuidador, educador, provedor e trabalhador correspondem a um quadro tradicional da função paterna. Duas outras categorias se colocam em pólos opostos: o pai como disciplinador e o pai lúdico, a primeira, diretamente relacionada à função paterna e à dinâmica familiar, é pautada na autoridade de quem coloca "a lei"; a segunda, em uma vertente igualitária de um pai companheiro e amigo.

O Grupo 1 vive em uma cidade urbanizada, com relações mais democráticas no casal, onde o pai cuida tanto quanto a mãe: "é aquele homem que nos ajuda para as coisas que a gente precisa, que cuida da gente" (menina, 11 anos). No Grupo 2, o pai provê e é bom:

Meu pai trabalha, só chega umas oito horas da noite, umas sete. Ele vem, dá dinheiro à mainha. De manhã, ele deixa o dinheiro pra mainha comprar comida e sai pra trabalhar sete ou oito horas da manhã. Aí ele chega e dorme pra ir pro trabalho amanhã (menina, 8 anos).

O significado de "ser bom", conforme visto no estudo anterior (Rabinovich \& Moreira, 2008), é "não bater". Parece retratar uma função tradicional paterna, ou ocorrer uma idealização desta figura, em alguns casos ausentes. Aparece também a visão de pai como "aquele que não faz nada" (em função do desemprego): "O que é ser pai? Não sei isso não. O que seu pai faz? Não faz nada, só minha mãe que faz. Mas o que é ser pai? Não faz nada" (menino, 7 anos). Petrini e cols. (2007), abordando a questão da família e da pobreza na mesma região em que foram coletados os dados do Grupo 2, revelaram que o pai é muito mais ausente do que a mãe e por vezes desconhecido. Aparece pouco na fala dos participantes e, em determinados casos, é idealizado, os autores apontam para a necessidade de mais estudos referentes a este fator.

No Grupo 3, semelhante à definição de família, o pai se 
apresenta lúdico, podendo-se supor que a família convive de um modo menos hierárquico: "é legal, ele (o pai) brinca com a gente, faz um monte de palhaçada" (menina, 10 anos). $\mathrm{O}$ Grupo 4 representa um aspecto mais tradicional da família popular, em que cabe ao pai educar, dar o destino, dizer o que é certo ou errado: "ser pai é uma grande responsabilidade de ensinar os filhos, fazer tudo e não deixar que seja quando crescer uma pessoa assim, marginal... Tem uma responsabilidade muito grande de criar os filhos" (menina, 11 anos).

Portanto, pode-se observar uma diferença ligada ao nível sócio-educacional, uma vez que o pai é visto de modo mais amigo e próximo no nível mais alto do que no mais baixo, em que o pai é compreendido como tendo atribuições mais tradicionais. Para analisar o significado de mãe, serão utilizadas as mesmas categorias empregadas para a concepção de pai, acrescentando-se: (a) cuida de tudo: caracterizando aquelas mães que cuidam da casa, fazem comida, dentre outras; (b) amiga: é a mãe que conversa, dá atenção; (c) tem filho: é a mãe que fica grávida e dá à luz; (d) outros: nesta categoria foram agrupados os seguintes tipos de concepções, divididas conforme a quantidade de respostas, $\left(\mathrm{d}_{1}\right)$ duas respostas: filho ajuda a mãe; $\left(\mathrm{d}_{2}\right)$ uma resposta: tarefa difícil; tem características negativas (é chata); não é violenta (não maltrata). Os dados obtidos encontram-se na Tabela 4.

Tabela 4

Distribuição das frequências das respostas sobre as concepções de mãe apresentadas pelos quatro grupos

\begin{tabular}{lccccc}
\hline \multicolumn{1}{c}{ O que é mãe } & Grupo 1 & Grupo 2 & Grupo 3 & Grupo 4 & Total \\
\hline Cuidadora & 9 & 4 & 7 & 4 & 24 \\
Educadora & 4 & 1 & 5 & 5 & 15 \\
Cuida de tudo & 2 & 4 & 3 & 6 & 15 \\
Lúdica & 5 & 2 & 5 & 2 & 14 \\
Afetiva & 4 & 1 & 3 & 6 & 14 \\
Disciplinadora & 2 & 2 & 3 & 1 & 8 \\
Provedora & - & 2 & - & 3 & 5 \\
Trabalhadora & 2 & 1 & - & 2 & 5 \\
Amiga & 2 & - & 1 & 2 & 5 \\
Boa & - & 4 & - & - & 4 \\
Tem filho & 1 & 2 & 1 & - & 4 \\
Outros & - & 1 & 1 & 3 & 5 \\
Não respondeu/não sabe & 3 & 1 & 1 & - & 5 \\
$\mathrm{n}^{\mathbf{0}}$ de respostas/ $\mathrm{n}^{\mathbf{0}}$ de participantes & $31(n=15)$ & $24(n=15)$ & $29(n=15)$ & $34(n=15)$ & $118(n=60)$ \\
\hline
\end{tabular}

As concepções mais encontradas são as de mãe cuidadora, educadora, assim como aquela que cuida de tudo. $\mathrm{O}$ aspecto lúdico aparece com menor frequência do que a encontrada no pai, sendo o aspecto afetivo mais destacado nela. A categoria provedora e trabalhadora é menos frequente do que a encontrada no pai. Porém, no aspecto de disciplina, os dois se assemelham, a capacidade de engravidar aparece como própria da mãe. Semelhante ao pai, a mãe do Grupo 1 aparece como quem cuida, portanto, ambos se ocupam dos cuidados:

Ser mãe não é jogo fácil. Tem que comandar os filhos, tem que levar à escola, fazer a lição, cuidar, dar banho, não é jogo mole, é jogo duro. Porque alguns filhos desobedecem, demoram pra tomar banho, demoram pra botar roupa, demoram para arrumar a bagunça no quarto, não é jogo mole não (menino, 6 anos).

Apesar de reconhecer as mudanças familiares, Jablonski $(1999,2007)$ relata que ainda é a mulher quem gasta mais tempo com o cuidado dos filhos, como também na administração e execução das tarefas domésticas. No Grupo 2, diferente do pai, a mãe basicamente cuida, e semelhante ao pai, "é boa", reforçando a idéia de papéis tradicionais familiares: "minha mãe fica em casa me cuidando. Me leva pra cá pra escola. Eu vou pra escola umas sete horas da manhã pra estudar e mainha fica em casa arrumando as coisas de casa até buscar A. (irmão)" (menina, 8 anos). Na pesquisa de Petrini e cols. (2007), que abordou famílias de baixa renda, as mães aparecem como figuras fundamentais, que determinam o momento inicial da vida dos entrevistados e sua base, sendo sua principal referência.

No Grupo 3, a mãe cuida, educa e brinca, enfatizando o aspecto positivo da vivência dessas crianças em relação às suas famílias: "é legal, ela me diverte, às vezes quando precisa ela chama a atenção" (menina, 10 anos); "mãe é ser a mulher que lava a louça, mãe é ser a dona da casa que faz o almoço de vez em quando, só quando é domingo, sábado, mãe também cuida da gente" (menina, 7 anos).

No Grupo 4, a mãe cuida de tudo e é afetiva, equivalendo ao pai que educa: "mãe é bom porque dá carinho, mais amor, mais abraço, e não bate tanto, mas tem que ter mais atenção com a mãe porque ela quando morrer, aí vou sentir mais falta" (menino, 11 anos). Portanto, a figura materna é vista como quem cuida e se ocupa da organização da casa e dos filhos, educando e disciplinando. 
Os significados de irmão foram agrupados em sete categorias: (a) brinca: entretem-se juntos em jogos infantis; (b) presta ajuda: colabora, protege, apóia ou cuida um do outro; (c) ensina: instrui, aconselha ou dá exemplos; (d) faz companhia: é amigo, passeia junto, acompanha o irmão mesmo quando os pais não estão; (e) atrita: pirraça, irrita, briga ou bate; (f) é confidente: conta ou ouve segredos; (g) significado afetivo: é carinhoso, amoroso. Tais dados são apresentados na Tabela 5.

Tabela 5

Distribuição das frequências das respostas sobre as concepções de irmãos apresentadas pelos quatro grupos

\begin{tabular}{lccccc}
\hline \multicolumn{1}{c}{ O que é irmão } & Grupo 1 & Grupo 2 & Grupo 3 & Grupo 4 & Total \\
\hline Brinca & 10 & 13 & 12 & 11 & 46 \\
Presta ajuda & 8 & 5 & 7 & 7 & 27 \\
Ensina & 2 & 4 & 2 & 5 & 13 \\
Faz companhia & 5 & 4 & - & 2 & 11 \\
Atrita & 2 & 3 & 2 & 3 & 10 \\
Confidente & 1 & - & 2 & 3 & 6 \\
Significado afetivo & - & 02 & - & 1 & 3 \\
$\quad \mathrm{n}^{\mathbf{0}}$ de respostas $/ \mathrm{n}^{\mathbf{0}}$ de participantes & $28(n=15)$ & $31(n=15)$ & $25(n=15)$ & $32(n=15)$ & $116(n=60)$ \\
\hline
\end{tabular}

Irmãos, essencialmente, servem para brincar, mas também prestam ajuda mútua e ensinam: "para ficar junto com você nas aventuras, brincar e cuidar da M. (irmã)" (menino, 9 anos, Grupo 1). Mesmo que atritem, são companhias com as quais se pode contar sempre. Todos os participantes souberam responder esta questão e de forma rápida, o que pode refletir a grande familiaridade com este membro da família. Este resultado se assemelha ao anteriormente obtido nos estudos de Rabinovich e Moreira (2008) com crianças paulistas. Relativamente às diferenças inter-grupais, os grupos urbanos 1 e 2 atribuem aos irmãos fazer companhia, devido à diminuição do tamanho do núcleo familiar e da vida intramuros:

Se o pai e a mãe tiverem em casa e o irmão estiver doente, ai o outro irmão pode ajudar, pode brincar, pra não brincar sozinha, pode ter sempre uma outra pessoa pra gente poder brincar, pra criar uma dança também, a gente tem uma outra pessoa, pra quando a gente precisar dela, a gente sempre ter. Porque, se os pais morrerem, ainda tem a irmã pra brincar, pra poder sair com as pessoas, pra também a tristeza não vir e ficar só a felicidade com o irmão (menina, 8 anos, Grupo 1).

Opostamente, as crianças do Grupo 3 não mencionam os irmãos como companhia, associado ao contexto familiar mais amplo e à maior liberdade para permanecerem na rua.

Finalmente, as concepções sobre avós receberam um número bem mais elevado de respostas (106) do que as de avôs (65), o que pode sinalizar maior familiaridade com elas. Para ambos, as categorias que mais apareceram foram: (a) lúdico(a): brinca, é divertido(a), passeia ou é engraçado(a); (b) agrada: dá ou faz coisas que gosta, elogia, dá dinheiro ou faz comida gostosa como bolo (este somente referindo-se às avós); (c) afetivo: é carinhoso, amoroso; (d) cuidador(a): cuida dos netos, cria-os, leva-os para a escola ou ainda os ajuda e protege quando necessário.

Assim como o pai, o avô é concebido mais como lúdico (18 respostas), fica evidente também que agrada os netos dando ou fazendo coisas que gostam (13 respostas), aspecto mais enfatizado nas avós (27 respostas), que, em menor escala, também são lúdicas (16 respostas). Porém, são mais afetivas (15 respostas) e cuidadoras (14 respostas) do que os avôs (sete e seis respostas respectivamente).

Uma menina com 8 anos (Grupo 1) descreve o que é ser avó assim: "fazer bolo pra agradar, fazer várias coisas, é trazer brinquedos, deixar a diversão acontecer mais do que deixar mais saudável. Sai mais pra se divertir, pra gente curtir mais". A descrição feita por um menino com 8 anos (Grupo 2) foi "avó fica dando coisa boa ao neto. Fica olhando o neto, se ele for pra rua, se o neto for pra rua, pra um lugar longe tem que olhar". Sobre o avô, uma menina com 7 anos (Grupo 3) afirma: "é bom porque ele de vez em quando ele leva a gente pra passear na praia, ele leva a gente pra piscina, também pro shopping". Uma menina de 9 anos (Grupo 4) diz que o avô é "legal, ele brinca comigo".

\section{Considerações finais}

Devido à dispersão das respostas em vários conteúdos, os resultados deste estudo podem apenas indicar tendências no modo como crianças baianas vivenciam e definem suas famílias e seus membros. As crianças conceberam sua família não apenas como nuclear, mas incluíram também outros parentes, esta visão de família extensa ocorreu nos quatro grupos, independente da condição sócio-educacional ou de se tratar de crianças provenientes da capital ou do interior.

Ao responder "O que é família para você?", os participantes destacaram os cuidados e o aspecto afetivo, sendo que as crianças de Salvador, cujos pais apresentam nível sócio-educacional baixo, tiveram dificuldade de 
formular uma resposta a essa questão. As crianças baianas destacaram, portanto, o aspecto cuidador e protetor atribuído à família.

Igualmente, as concepções de mãe mais encontradas foram as de cuidadora do filho, educadora, assim como aquela que cuida de tudo. $\mathrm{O}$ aspecto lúdico apareceu com maior frequência no pai do que na mãe, todavia o aspecto afetivo foi mais destacado nesta, o pai foi destacado com maior frequência como provedor e trabalhador, porém, quanto à disciplina, os dois se assemelharam. Deste modo, o olhar das crianças indicou haver mudanças nos papéis tradicionais associados ao pai e à mãe, transformações que ocorreram em menor intensidade nos ambientes menos favorecidos e urbanizados.

Os irmãos foram evidenciados como figuras importantes nos quatro grupos, tendo duas características se destacado: o de ser parceiro de brincadeiras e o de prestar ajuda, apesar de algumas referências a atritos entre eles, em acordo com pesquisa anteriormente realizada por Rabinovich e Moreira (2008). Os papéis dos avós são relevantes, sendo o avô mais lúdico e a avó mais afetiva e cuidadora, acrescentando-se o aspecto do agrado, principalmente das avós.

Portanto, esse estudo sugere uma tendência à existência de relações mais democráticas e menos hierarquizadas na família baiana. Revelou, ainda, diferenças associadas ao sexo do progenitor, ao local da moradia e ao nível sócio-educacional. Porém, o estudo parece apontar que os papéis de geração se mostram mais nítidos do que os de gênero como fatores na compreensão da criança sobre a família. Sugere-se um estudo posterior para aprofundar os significados atribuídos pelas crianças aos conteúdos de suas definições, detalhando, por exemplo, questões de gênero e de gerações. Seria também interessante investigar se as respostas das crianças variam de acordo com diferentes arranjos familiares.

\section{Referências}

Arriagada, I. (2000). Nuevas familias para um nuevo siglo? Paidéia (Ribeirão Preto), 10, 28-35.

Bardin, L. (1977). Análise de conteúdo. Lisboa: Edições 70.

Biasoli-Alves, Z. M. M. (2008). Cuidado e negligência na educação da criança na família. In L. Moreira \& A. M. A. Carvalho (Orgs.), Família e educação: Olhares da psicologia (pp. 19-32). São Paulo: Paulinas.

Bronfenbrenner, U. (1996). A ecologia do desenvolvimento humano: Experimentos naturais e planejados (M. A. V. Veronese, Trad.). Porto Alegre: Artes Médicas. (Original publicado em 1979)

Bronfenbrenner, U. (2004). Making human beings: Human bioecological perspectives on human development. California: Sage.

Carvalho, A. M. A., Beraldo, K. E. A., Pedrosa, M. I., \& Coelho, M. T. (2004). O uso de entrevistas em estudos com crianças. Psicologia em Estudo, 9, 291-300.

Cruz, H. M. (2008). Família é quem cuida de mim: Narrativas de identidade de jovens adultos criados em abrigo. Rio de Janeiro: Instituto Noos.
David, C. (2001). L'enfant roi. L'Expansion, 635, 37-59.

Godelier, M. (2004). Métamorphoses de la parenté. Monrouge: Fayard.

Hviid, P. (2006). Dimensões de tempo segundo a percepção de crianças de seu próprio desenvolvimento. Revista Brasileira de Crescimento e Desenvolvimento Humano, 16(2), 69-76.

Jablonski, B. (1999). Identidade masculina e o exercício da paternidade: De onde viemos e para onde vamos. In T. Féres-Carneiro (Org.), Casal e família: Entre a tradição e a transformação (pp. 55-69). Rio de Janeiro: NAU.

Jablonski, B. (2007). O cotidiano do casamento contemporâneo: A difícil e conflitiva divisão de tarefas e responsabilidades entre homens e mulheres. In T. Féres-Carneiro (Org.), Família e casal: Saúde, trabalho e modos de vinculação (pp. 203-228). São Paulo: Casa do Psicólogo.

Krantz, B., \& Rasmusson, B. (1995). Changing perspectivs and approaches: Swedish research on children and the urban environment. Architecture \& Comportement/ Architecture \& Behavior, 11, 27-34.

Mann, B. J., Borduin, C. M., Borduin, B. J., \& Sylvester, C. E. (1992). Children's concepts of the family. Journal of the American Academy of Child and Adolescent Psychiatry, 31, 478-488.

Moreira, L. V. C. (1999). Concepções de mães usuárias de creche sobre educação de filhos. Dissertação de Mestrado não-publicada, Faculdade de Educação, Universidade Federal da Bahia, Salvador, BA.

Moreira, L. V. C. (2005). Concepções e práticas de pais sobre educação de filhos. Tese de Doutorado não-publicada, Faculdade de Filosofia, Ciências e Letras de Ribeirão Preto, Universidade de São Paulo, Ribeirão Preto, SP.

Petrini, J. C., Moreira, L. V. C., Alcântara, M. A. R., Reis, L. P. C., Santos, J. E. F., \& Fonseca, R. S. S. (2007). Combate à pobreza e às desigualdades sociais: Rotas da inclusão. Manuscrito não-publicado, Universidade Católica do Salvador, Salvador, BA.

Rabinovich, E. P. (1994). O modo de morar e a vida cotidiana como indicadores qualitativos do desenvolvimento infantil: Um estudo de uma população de crianças de 0-3 anos na zona rural do Piauí, Brasil. Caderno de Desenvolvimento Infantil, 1, 62-75.

Rabinovich, E. P., \& Gallo, P. R. (2005). Estudo de uma comunidade quilombola do Carmo-São Roque, SP. In J. C. Petrini \& V. R. S. Cavalcanti (Orgs.), Família, sociedade e subjetividades: Uma perspectiva multidisciplinar (pp. 195-209). Petrópolis, RJ: Vozes.

Rabinovich, E. P., \& Moreira, L. V. D. C. (2008). Significado de família para crianças paulistas. Psicologia em Estudo, $13,447-455$.

Sarti, C. (2004). Algumas questões sobre família e políticas sociais. In C. Jacquet \& L. F. Costa (Orgs.), Família em mudança (pp. 177-192). São Paulo: Companhia Ilimitada.

Sirota, R. (2001). Emergência de uma sociologia da infância: Evolução do objeto e do olhar. Cadernos de Pesquisa, 112, 7-22. 
Skantze, A. (1995). Experiencing and interpreting city architecture. Architecture \& Comportement/Architecture \& Behavior, 11, 5-10.

Tudge, J. (2008). A teoria de Urie Bronfenbrenner: Uma teoria contextualista? In L. V. C. Moreira \& A. M. A. Carvalho (Orgs.), Família e educação: Olhares da psicologia (pp. 209-231). São Paulo: Paulinas.

Welti, C. (2002). Adolescents in Latin America: Facing the future with skepticism. In B. B. Brown, R. W. Larson, \& T. S. Saraswathi (Eds.), The world's youth: Adolescents in eight regions of the globe (pp. 276-306). Cambridge, Cambridge University Press.

Lúcia Vaz de Campos Moreira é Professora Doutora do Programa de Pós-graduação em Família na Sociedade Contemporânea da Universidade Católica do Salvador, campus da Federação.

Elaine Pedreira Rabinovich é Professora Doutora do Programa de Pós-graduação em Família na Sociedade Contemporânea da Universidade Católica do Salvador, campus da Federação.

Célia Nunes Silva é Professora Associada I do Departamento de Neurociências e Saúde Mental da Faculdade de Medicina da Universidade Federal da Bahia.

Recebido: $29 / 05 / 2008$

$1^{a}$ revisão: 04/02/2009

Aceite final: 10/02/2009 